\title{
THREE NEW SPECIES OF PANORPIDAE (MECOPTERA)
}

\author{
By Fung Ying Cheng \\ Harvard University and University of Taiwan
}

The new species of Mecoptera described below have come to my attention during a study of Old World Panorpidae.

\section{Genus Panorpa}

Panorpa chiensis, n. sp.

\author{
(Pl. 5, figs. 1-3 ; text-fig. 1,A)
}

Body mostly black; vertex and rostrum uniformly shining black; thorax black dorsally, reddish brown laterally; the 1st-9th abdominal segments of male shining black dorsally and ventrally; the hind process of the third tergite is short and stout, unusually broad, with more or less truncate apex, and is in contact with the very short conical median projection of the fourth tergite; the 6th-8th segments not prolonged. Fore wing: length, 17.2-19 mm.; width, 4.7-5.2 mm.; membrane hyaline, markings brownish black; pterostigma not very prominent. Hind wing: length 15.5$17 \mathrm{~mm}$.; width, 4.5-5.1 mm. of genitalia: genital bulb slender; coxopodites long, their inner margins bearing a rounded process distally and a sharp tooth-like process medianly; harpagones slender, the outer margin greatly concave near the base, inner margin with a triangular process and a true basal lobe, which bears a tuft of bristles; the apex of harpagones usually truncate; hypandrium broad basally; branches of hypovalvae broad distally, its distal outer margins fold upward to form a triangular plate on the edge, the apex folded upward to form a rounded distal end, which reaches to the base of the harpagones; parameres simple, each consisting of a simple stalk, which broadens distally with a somewhat twisted apical portion, its distal inner margin usually bearing a row of short barbs; preëpiproct narrow towards apex, with very small U-shaped distal incision; aedeagus with prominent finger-like ventral processes, apical processes finger-shaped, lateral processes very short, sharp tooth-like, extended upward. 
q unknown.

Holotype ( 8 ) : Chi-i, Korea; July 5, 1940; in the Museum of the Institute of Zoology, Academia Sinica, Shanghai.

Paratypes: Same collecting data as holotype: 1 , in the above Institute of Zoology; 1 , in the Museum of Comparative Zoology; 1 , in Cheng Collection.

At first sight this species looks like Panorpa approximata. Esben-Peterson, but the peculiar shape of the genitalia in the male easily separates the two species.

Genus Neopanorpa

Neopanorpa baviensis, n. sp.

(Pl. 5, figs. 6-8; text-fig. 1,B)

Body grayish brown, vertex grayish brown posteriorly, black anteriorly; rostrum brown, with grayish brown longitudinal stripe on each side; thorax brown, meso- and metanotum with grayish brown median streak; the 1st-9th abdominal segments of male grayish brown dorsally and ventrally, median process of $3 \mathrm{rd}$ tergite short, extending a little beyond the middle of the 4 th tergite. Fore wing: length, $15.5 \mathrm{~mm}$; width, $3.2 \mathrm{~mm}$., membrane slightly hrown, markings blackish brown; pterostigmal band broad, complete, with broad basal branch and apical branch; basal band complete; apical band very large, connected with the pterostigmal band at both the front and hind margins; basal spot obscure; marginal spot present; pterostigma not very prominent. Hind wing: length, $15 \mathrm{~mm}$; width, 3.1 mm., similar to fore wings, except that the basal band is indicated only by a spot at the hind margin. of genitalia: genital bulb slender; coxopodites long with truncated apex; harpagones slender, the outer margin slightly concave at the middle, with a row of short black hairs at the middle; inner margin with a slightly projecting median portion and a small basal lobe which bears a small tooth-like process on its dorsal edge; hypandrium long; branches of hypovalvae slender, the basal portions wide apart, the distal portions, slightly overlapping each other; the apex of hypovalvae usually reaching to the middle of the harpagones; parameres simple, small and curved; preëpiproct slightly enlarged distally and with truncated apex; aedeagus small, with a pair of tooth-like processes on its dorsal edge, the 
apical processes united, lateral processes tooth-like, usually bent upwards.

\& unknown.

Holotype ( $\hat{o}$ ): Mt. Bavi 800-1000 m., Tonkin; July, 1941; A. DeCooman; in Heude Museum, Shanghai.

Paratype: 1 of same collecting data as holotype, in Cheng Collection.

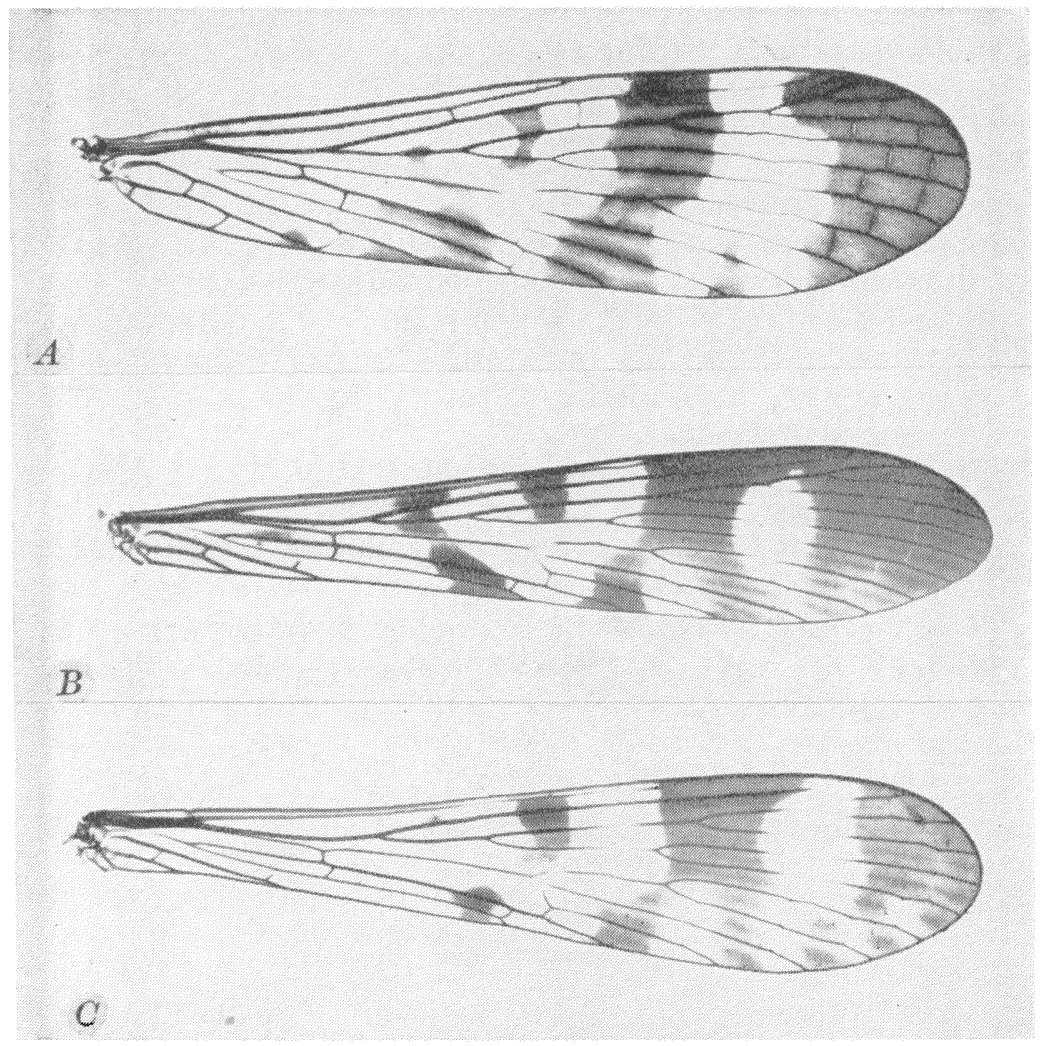

1:xing. 1. A, Panorpa chrensis, n. sp., tore wing. B, Neopinurpa bariensis, n. sp., fore wing. C, Neopanorpa contracta, n. sp., fore wing.

This species differs from other described Neopanorpa by its rather sharp wing apex and the very long branches of the hypovalvae in the male. 
Neopanorpa contracta, $\mathrm{n}$. sp.

(Pl. 5, figs. 4-5; text-fig. 1,C)

Body mostly brown; vertex sooty brown, rostrum uniformly grayish brown; thorax deep brown dorsally; the 1st-7th abdominal segments of female deep brown dorsally, last few abdominal segments light brown. Fore wing: leng th, $14.5 \mathrm{~mm}$.; width, $3.2 \mathrm{~mm}$.; membrane hyaline, markings grayish brown; pterostigmal band complete, with a broad basal branch and apical branch; basal band represented by a spot; apical band large with two hyaline spots; basal spot absent; marginal spot large; pterostigma not very prominent; the basal portion of wing is very long and narrow. Hind wing: length, $13.2 \mathrm{~mm}$.; width, $3 \mathrm{~mm}$.; similar to the fore wing. \& genitalia: subgenital plate broad with wide V-shaped distal incision; internal skeleton small, the posterior arms of the plate rather long, twisted, with narrow apex, the axis shorter than the posterior arms, extending a little beyond the plate.

s unknown.

Holotype ( ㅇ ) : Darjeeling, India; May, 1938; Maa; in Maa Collection.

Paratype: 1 \% same collecting data as holotype; in Cheng Collection.

This species is easily distinguished from others of the genus by the very long and contracted basal portion of the wings. The shape of the female genitalia also makes its recognition easy.

\section{Explanation to Plate 5}

Figs. 1-3. Panorpa chiensis, n. sp. 1, ventral view of genital bulb of $\hat{\delta}$; 2 , preëpipioct of $\hat{\delta} ; 3$, ventral view of genital bulb of $\hat{\sigma}$ with harpagones removed. Figs. 4-5. Neopanorpa contracta, n. sp. 4, subgenital plate of o ; 5, internal ske!eton of $ᄋ$. Figs. 6-8. Neopanorpa baviensis, n. sp. 6, ventral view of genital bulb of $\hat{\delta} ; 7$, preëpiproct of $\hat{\delta} ; 8$, genital bulb of $\hat{\delta}$ with harpagones removed. 

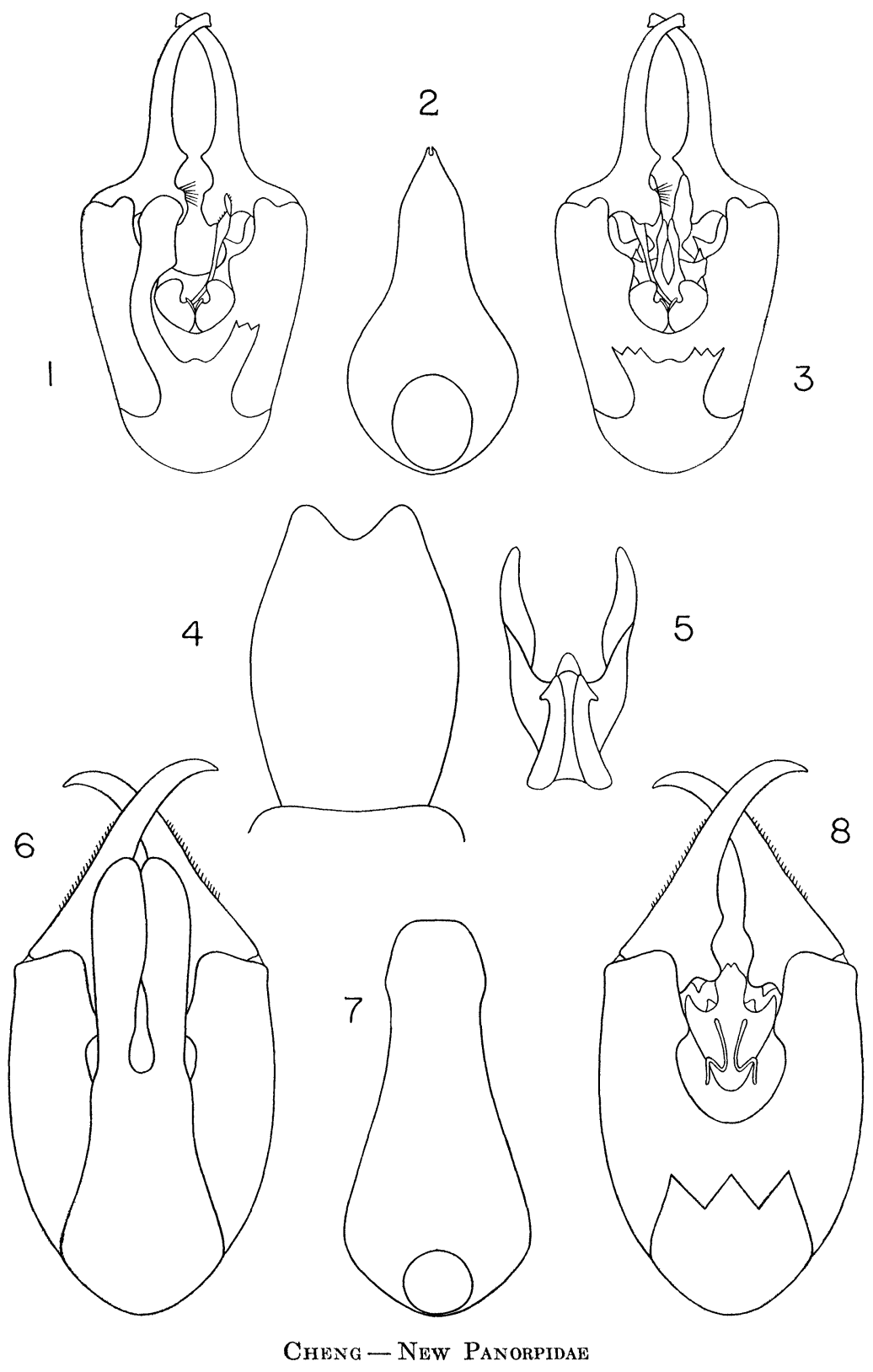

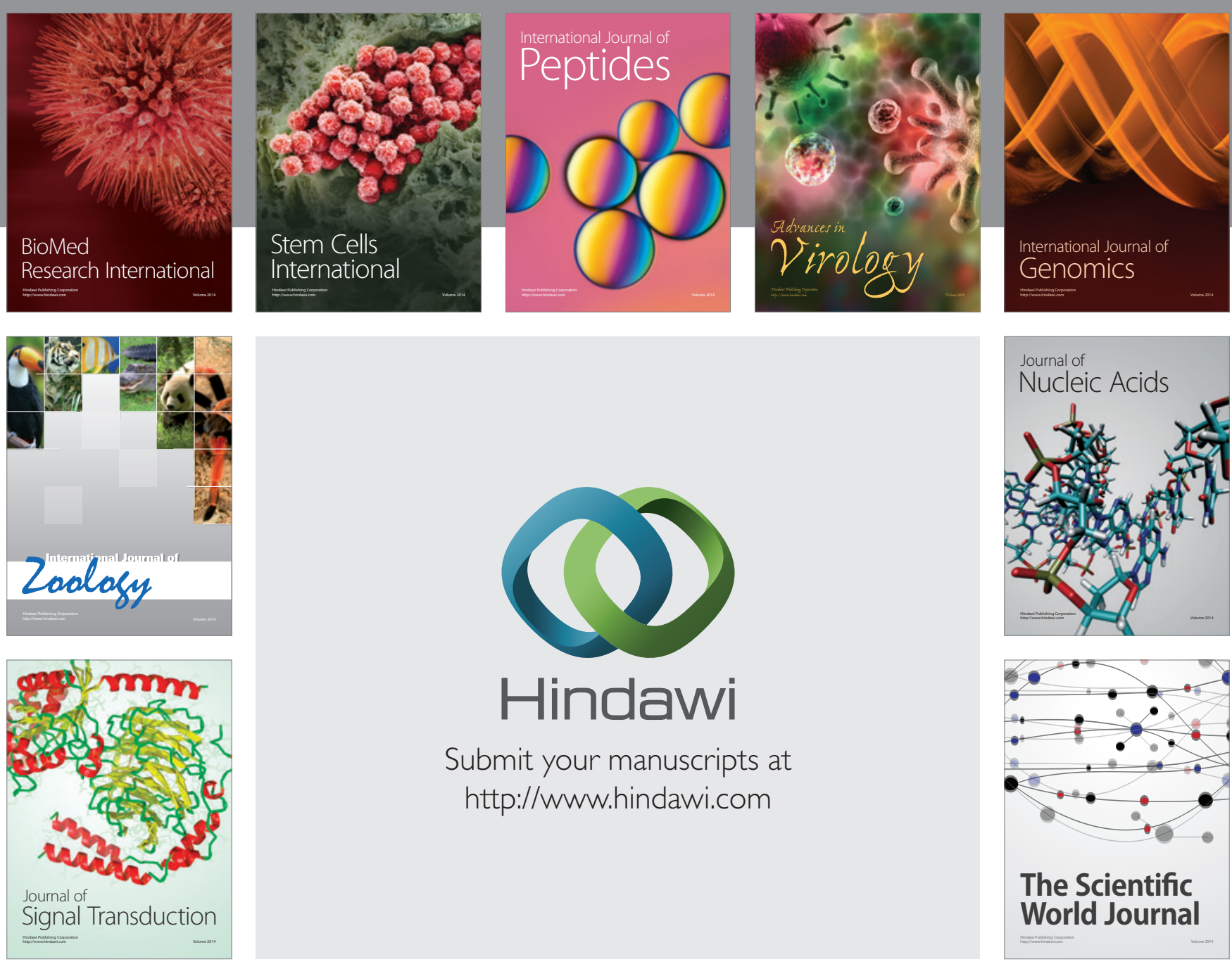

Submit your manuscripts at

http://www.hindawi.com
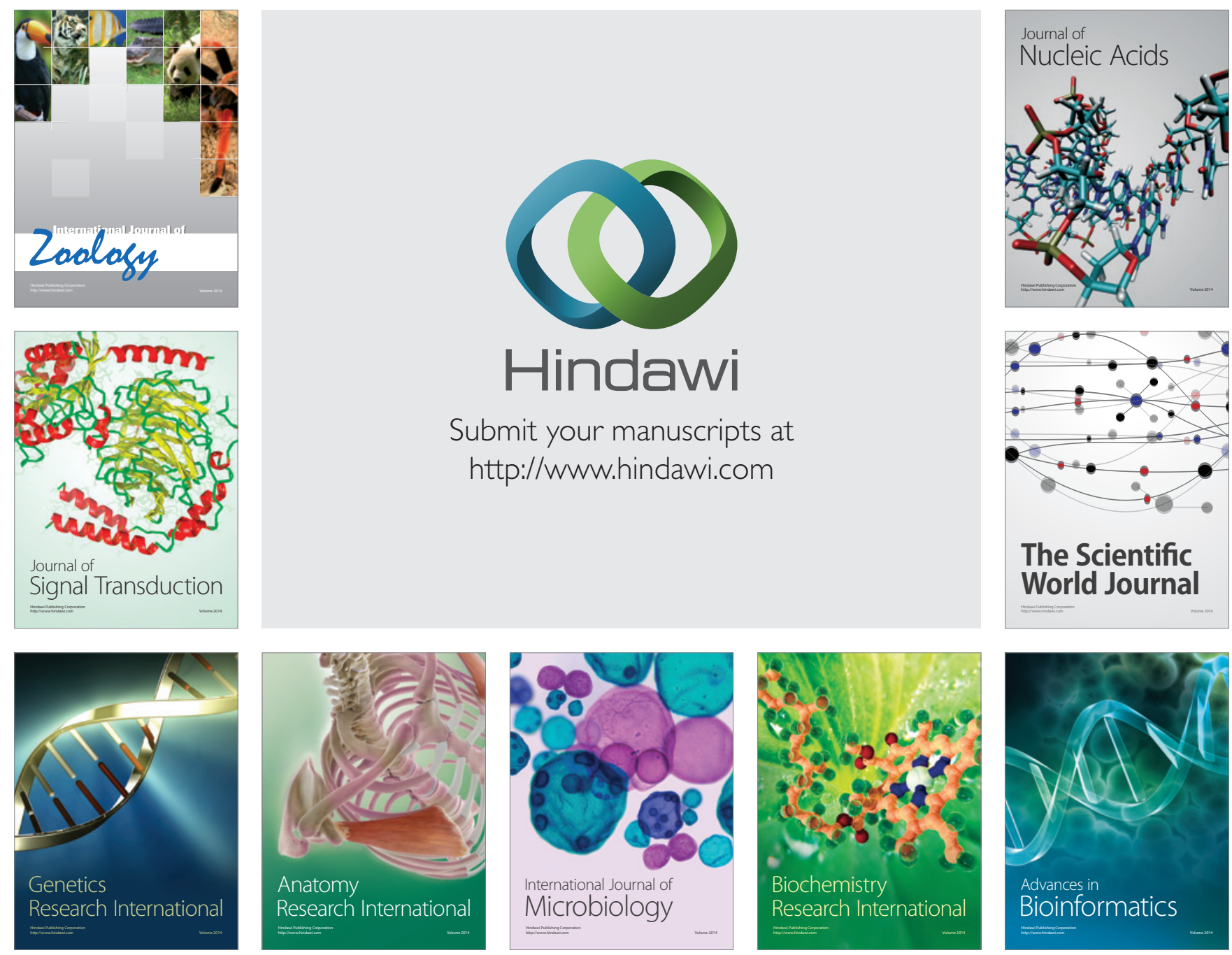

The Scientific World Journal
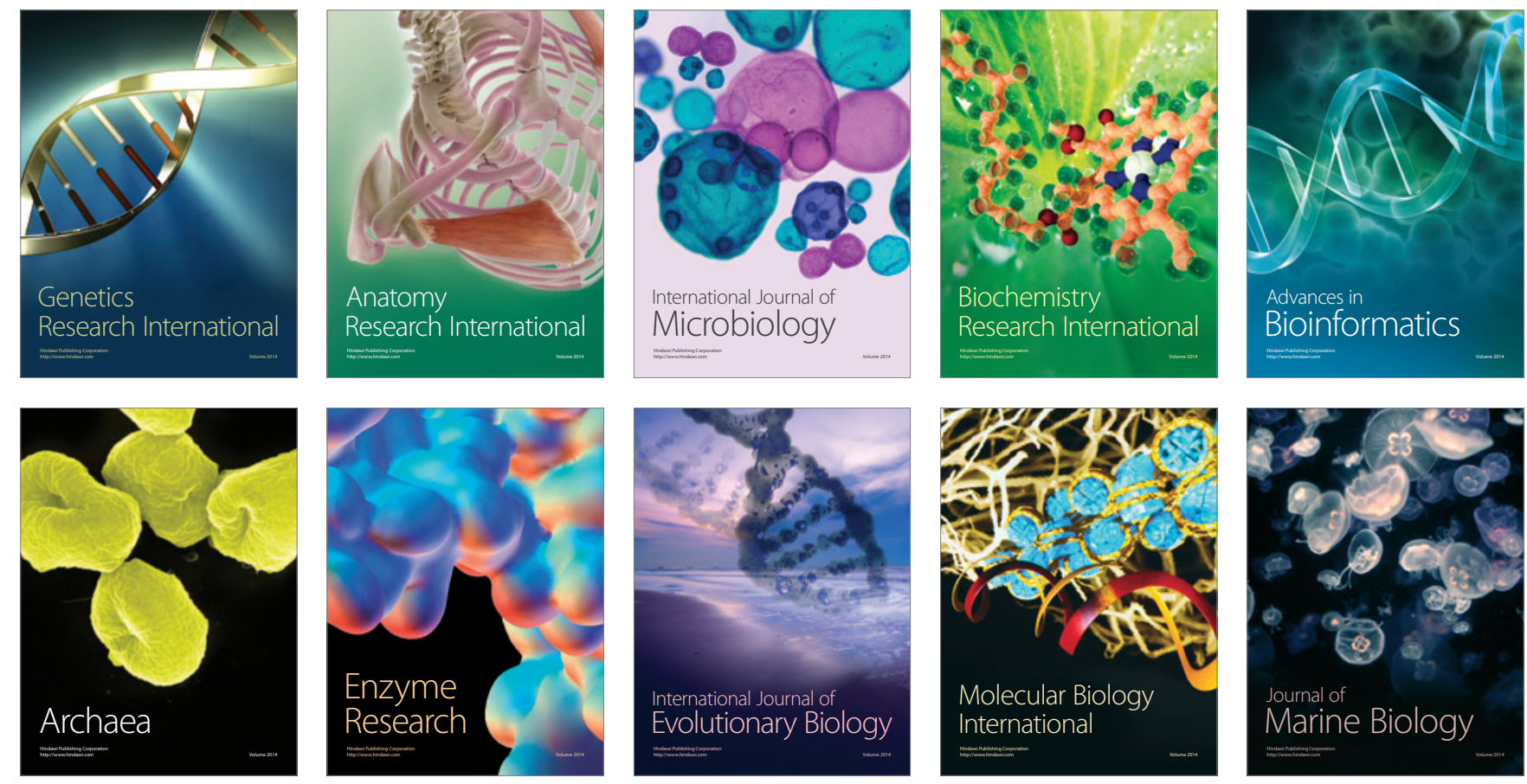